\title{
How effective are body mass index and body muscle weight on cardiopulmonary resusitation?
}

\author{
(D)Ejder Saylav Bora' ${ }^{1}$, (DAdem Çakır ${ }^{2}$, (1)Adnan Yamanoğlu ${ }^{1}$ \\ ${ }^{1}$ İzmir Atatürk Research and Training Hospital, Department of Emergency Medicine, İzmir, Turkey \\ ${ }^{2}$ Başakşehir Çam ve Sakura City Hospital, Department of Emergency Medicine, İstanbul, Turkey
}

Cite this article as: Bora ES, Çakır A, Yamanoğlu A. How effective are body mass index and body muscle weight on cardiopulmonary resusitation? J Health Sci Med 2022; 5(1): 104-108.

\begin{abstract}
Aim: The purpose of this study is searching the effect of BMI and BMW on the quality of CPR and the state of exhaustion applied by the professionals in the emergency department.

Material and Method: The software of the CPR education manikin was used in order to count and measure the number and the depth of the compressions and their correspondence to each other during the first and the second minutes of the procedure. Five cycles of chest compressions were asked to do from the rescurers. Each rescuer has handed the task of applying pressure over to his/her following team member after two minutes. Borg tiredness scores were asked to the rescuers and recorded at the end of each-minute period.

Results: The mean depth of pressure, the number of pressure attempts applied and the number of superficial compressions of the participants who were grouped due to their BMI showed no statistically meaningful difference. Both in the mean values of Borg tiredness scores which were calculated at the end of the first and second minutes; the group with lower BMW showed higher exhaustion significantly and this group couldn't make sufficient compressions by means of depth and number, and also the latter showed more exhaustion compared to the first.

Conclusion: It is considered that choosing the health workers who are going to apply CPR among individuals with higher BMW or encouraging the workers in those departmnets who frequently apply CPR to be more interested in sports activities could be a promoting factor for having good quality CPR and reducing mortality as well.
\end{abstract}

Keywords: Cardiopulmonary resuscitation, body mass index, body muscle weight, borg fatigue scale

\section{INTRODUCTION}

Cardiopulmonary arrest is the sudden and unexpected cessation of breathing and/or circulation in a patient for any reason. It is clinically defined as the absence of cardiac mechanical activity. The clinical diagnosis is confirmed by unresponsiveness, absence of pulse, and apnea. Practices that involve efforts to resuscitate a person whose life has been interrupted in any way are called Cardiopulmonary Resuscitation (CPR) $(1,2)$. The 2020 AHA guideline draws attention to the importance of early recognition of cardiac arrest and early initiation of chest compressions by the rescuer (3).

High-quality chest compressions of at least 100-120 per minute in adult advanced cardiac life support, chest compression depth of at least $5-6 \mathrm{~cm}$ in adults. It is recommended to allow chest expansion after each compression, to reduce interruptions in compressions, to avoid overbreathing, and to change chest compressions every 2 minutes if more than one rescuer is present. There are not enough studies that draw attention to physical characteristics such as body mass index (BMI) or body muscle weight (BKA) of rescuers who will perform chest compressions. In addition, studies showing the effect of the victim's physical characteristics on chest compressions are also insufficient. This issue is not emphasized in the 2020 AHA guidelines (3).

Insufficient CPR quality was observed in studies conducted with nurses and nursing students (4). In a study examining the reasons for not performing adequate and effective chest compressions, weight, body mass index and female gender were found to be affecting factors. It is emphasized that individuals with higher body weight and body mass index perform more effective chest compression (5-9). 
The aim of this study is to investigate the effects of body mass index and body muscle weight on CPR quality and fatigue of rescuers who professionally perform CPR in emergency services.

\section{MATERIAL AND METHOD}

The study was carried out with the permission of İzmir Katip Celebi University Non-Interventional Clinical Researchs Ethics Committee (Date: 27.05.2021, Decision No: 281). All procedures were carried out in accordance with the ethical rules and the principles of the Declaration of Helsinki. The study was carried out between 01.05.2021 and 01.07.2021, by applying chest compression to the CPR manikin used for training purposes by emergency medicine residents working in a tertiary education and research hospital.

Using the software program of the CPR trainer dummy we used in our study, chest compressions applied by each rescuer were performed at 0-1.minute and 1-2.minutes. We calculated the number and depth of compressions as well as the number of superficial and appropriate chest compressions made by the practitioner in minute time intervals.

$\mathrm{CPR}$ rescue teams were formed in groups of two from 76 residents who participated in our study. Each rescue team was asked to apply chest compressions to the CPR trainer dummy for a total of 5 turns alternately. After each rescuer applied chest compressions for 2 minutes, he handed over the pressure application task to his teammate. The rescuers were asked and recorded their Borg fatigue scale (BFS) at the end of the $1^{\text {st }}$ and $2^{\text {nd }}$ minutes of each lap.

Segmented body analyzers are devices that work with the bio-impedance analysis method and measure by sending an electric current of 50 kilohertz $(\mathrm{kHz})$ to the body. Measurements of 76 residents who participated in our study were made with a segmented body analyzer. As a

\begin{tabular}{|clcl|}
\hline \multicolumn{3}{|c|}{ Borg } & Fatigue Scale $\mathbf{1 .}$ BFS and scoring parameters \\
\hline \multicolumn{1}{|c|}{ 15- graduated scale } & \multicolumn{1}{l|}{$\mathbf{1 0}$ - graduated scale } \\
6 & No Fatigue & 0 & Not hard at al \\
7 & fairly easy & 0,5 & Very very easy \\
8 & & 1 & Very easy \\
9 & Very easy & 2 & easy \\
10 & & 3 & moderate \\
11 & easy & 4 & \\
12 & & 5 & hard \\
13 & A little hard & 6 & \\
14 & & 7 & Very hard \\
15 & hard & 8 & \\
16 & & 9 & \\
17 & Very hard & 10 & Very very hard \\
18 & & & \\
19 & pretty hard & & \\
20 & Maximum fatigue & & \\
\hline
\end{tabular}

result of the measurement, data such as body mass index, body muscle weight, body fat ratio were obtained. After the necessary measurements were made, the data of the normal weight and overweight groups were used according to the BMI classification of the World Health Organization. Eight (10.6\%) of 76 resident physicians included in the study were not included in the study because they were in the obese group according to BMI classification and they were thought to distort the study data. The data of 68 residents who were suitable for the study were used.

Since there is no classification method for body muscle weight (BMW), the median value of BMW of 67 residents was calculated and two groups were formed as those with high and low muscle weight.

In our study, the average number of compressions, average depth of compression, average number of appropriate compressions, average number of superficial compressions and fatigue were compared in a group of 67 residents divided into two using body mass index (BMI) and body muscle weight (BMW).

In our study, those with chest compression depth below $50 \mathrm{~mm}$ and above $60 \mathrm{~mm}$ were accepted as faulty compressions, and those with $50-60 \mathrm{~mm}$ were considered suitable compressions.

\section{Statistical Analysis}

Statistical analyzes were performed using SPSS version 15 software. The conformity of the variables to the normal distribution was examined by visual (histogram) and analytical methods (Kolmogorov-Smirnov/ShapiroWilk tests). Descriptive analyzes were performed using median and interquartile ranges for non-normally distributed variables, and frequency tables for ordinal variables. Since there were non-parametric conditions, the variables were compared between groups using the Mann-Whitney U test. Cases where the P value was below 0.05 were considered as statistically significant results.

\section{RESULTS}

In this study if we evaluate demographic data; $64.7 \%$ of the 68 participants were male $(n=44)$ and the mean age was $31.27 \pm 4.22$ years. Parameters related to VCI and BMW values of the participants are given in Table 1. $64.7 \%$ of the participants were male and $35.3 \%$ were female. BMI and BMW were found to be significantly lower in women than in men. Both 1st and 2nd min of female cases. At the end of the study, it was seen that the mean score of the AQI was higher than that of the men (respectively, female ACS Scores were 1.min 12.59, while male ACS Points were $1 . \min 10.45 ; \mathrm{p}=0.016$; female ACS Points were 2.min 13.01, while male ACS Points were $2 . \min 11,59 ; \mathrm{p}=0.038)$. It was found that women were significantly more tired than men. 


\begin{tabular}{|c|c|c|c|c|}
\hline Parametre & Male & Female & $\mathbf{p}$ & Total \\
\hline $\begin{array}{l}\text { Number of } \\
\text { participant (\%) }\end{array}$ & $44(64.7)$ & $24(35.3)$ & - & $68(100)$ \\
\hline $\begin{array}{l}\text { Average on age } \\
( \pm s s)(y 11)\end{array}$ & $32.19 \pm 4.53$ & $30.23 \pm 2.59$ & 0.218 & $31.27 \pm 4.22$ \\
\hline BMI Median & 26.14 & 21.11 & $<0.001$ & 24.43 \\
\hline BMW Median & 36.43 & 23.58 & $<0.001$ & 33.89 \\
\hline BMI & & & 0.098 & \\
\hline Normal (n (\%)) & $22(56.4)$ & $17(43.6)$ & & $39(100.0)$ \\
\hline $\operatorname{High}(\mathrm{n}(\%))$ & $22(75.8)$ & $7(24.2)$ & & $29(100.0)$ \\
\hline BMW & & & 0.008 & \\
\hline $\begin{array}{l}\text { Low (BMW } \\
<33,91)(\text { n }(\%))\end{array}$ & $10(22.7)$ & $24(77.3)$ & & $44(100.0)$ \\
\hline $\begin{array}{l}\text { High BMW } \\
\geq 33,91(\mathrm{n}(\%))\end{array}$ & $34(100.0)$ & $0(0.0)$ & & $34(33.0)$ \\
\hline
\end{tabular}

When the ages of the cases and the quality of CPR were examined; It was observed that the BCS score increased significantly with increasing age $(\mathrm{p}<0.001)$, but the rate of incorrect compression decreased with increasing age $(p=0.026)$. This shows that while experienced health personnel make fewer false presses, fatigue occurs faster with increasing age.

Participants were divided into high and normal groups according to their BMI values, and the parameters measured in these participants were analyzed. The average compression depth of the participants grouped according to BMI, the number of compressions at the end of the $1^{\text {st }}$ and $2^{\text {nd }}$ minutes, and the $1^{\text {st }}$ and $2^{\text {nd }} \min$. There was no statistically significant difference between the mean pressure errors measured at the end of the study. Both $1^{\text {st }}$ and $2^{\text {nd }} \min$. On the other hand, in the mean BCS scores measured at the end of the study, it was found that patients with a high BMI had significantly less fatigue (Table 2 and Figure 1).

According to the BMW values of the participants, they were analyzed in two groups as high and low. The parameters measured in these participants were analyzed and the analysis results obtained are given in Table 3. It was observed that there was a statistically significant difference in all parameters measured for CPR compliance of the participants grouped according to BMW. According to these parameters, it was determined that the participants with low BMW could not create enough compressions, the number of incorrect compressions increased afterward, and they were more tired compared to the BCS score data (Table 3, Figure 2).

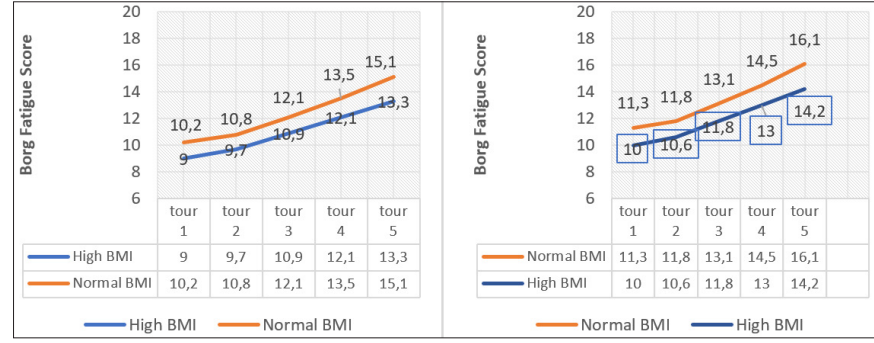

Figure 1. Comparison of BFS Score at the end of $1^{\text {st }}$ and $2^{\text {nd }}$ minutes in cases with normal and high BMI. a. $1^{\text {st }}$ minute BFS Score b. BFS Score at the end of the $2^{\text {nd }}$ minute

Table 2. Analysis of CPR parameters measured at the end of $1^{\text {st }}$ and $2^{\text {nd }}$ minutes of participants with normal and high BMI

\begin{tabular}{|lccc|}
\hline Parametre & $\begin{array}{c}\text { High BMI } \\
\text { Mean } \pm \text { Ss } \\
(\mathbf{n}=\mathbf{2 8})\end{array}$ & $\begin{array}{c}\text { Normal BMI } \\
\text { Mean } \pm \text { Rs } \\
(\mathbf{n}=4 \mathbf{4 0})\end{array}$ & $\mathbf{p}^{*}$ \\
\hline $\begin{array}{l}\text { Average Compression } \\
\text { Depth (mm) }\end{array}$ & $57.48 \pm 5.52$ & $56.38 \pm 6.84$ & 0.463 \\
$\begin{array}{l}\text { Number of Appropriate } \\
\text { Presses (0-1. Min) }\end{array}$ & $115.42 \pm 21.88$ & $110.31 \pm 27.34$ & 0.516 \\
$\begin{array}{l}\text { Number of Appropriate } \\
\text { Presses (1-2. Min) }\end{array}$ & $108.52 \pm 31.25$ & $89.68 \pm 42.28$ & 0.208 \\
$\begin{array}{l}\text { Incorrect Compression } \\
\text { Average (0-1. Min) }\end{array}$ & $12.15 \pm 23.92$ & $20.14 \pm 26.52$ & 0.498 \\
$\begin{array}{l}\text { Incorrect Compression } \\
\text { Average (1-2. Min) }\end{array}$ & $17.50 \pm 33.23$ & $40.32 \pm 37.25$ & 0.121 \\
$\begin{array}{l}\text { BFS Average Score (end } \\
\text { of 1. min) }\end{array}$ & $10.99 \pm 1.68$ & $12.42 \pm 1.54$ & 0.007 \\
$\begin{array}{l}\text { BFS Average Score (end } \\
\text { of 2. min) }\end{array}$ & $11.95 \pm 1.72$ & $13.28 \pm 1.53$ & 0.006 \\
\hline${ }^{*}$ Mann-Whitney U Test used & & & \\
\hline
\end{tabular}

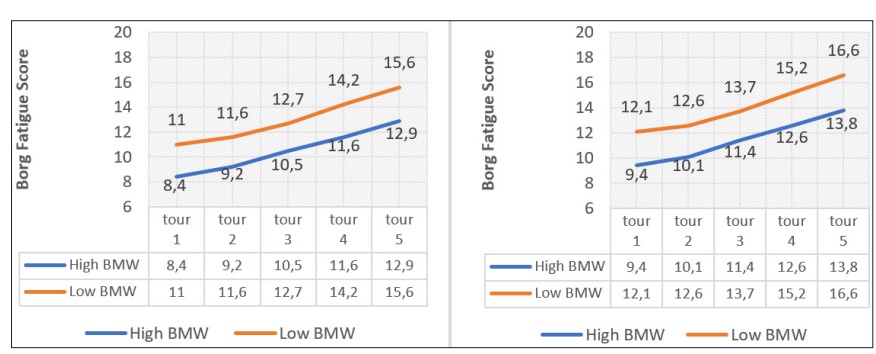

Figure 2. Comparison of BFS Score at the end of $1^{\text {st }}$ and $2^{\text {nd }}$ minutes in cases with high and low VKA. a. $1^{\text {st }}$ minute BFS Score b. BFS Score at the end of the $2^{\text {nd }}$ minute

Table 3. Analysis of CPR parameters measured at the end of $1^{\text {st }}$ and $2^{\text {nd }}$ minutes of BMW high and low cases

\begin{tabular}{|c|c|c|c|}
\hline $\begin{array}{l}\text { Parametre } \\
\text { For } 5 \text { Rounds of CPR }\end{array}$ & $\begin{array}{c}\text { High BMW } \\
\text { Mean } \pm \text { Ss } \\
(\mathbf{n}=34)\end{array}$ & $\begin{array}{c}\text { Low BMW } \\
\text { Mean } \pm \text { Ss } \\
(n=34)\end{array}$ & $\mathbf{p}^{*}$ \\
\hline $\begin{array}{l}\text { Average Compression } \\
\text { Depth (mm) }\end{array}$ & $59.22 \pm 4.04$ & $53.19 \pm 6.55$ & 0.004 \\
\hline $\begin{array}{l}\text { Number of Appropriate } \\
\text { Presses (0-1. Min) }\end{array}$ & $124.89 \pm 13.02$ & $100.28 \pm 27.59$ & 0.002 \\
\hline $\begin{array}{l}\text { Number of Appropriate } \\
\text { Presses (1-2. Min) }\end{array}$ & $122.92 \pm 11.26$ & $74.88 \pm 40.76$ & $>0.001$ \\
\hline $\begin{array}{l}\text { Incorrect Compression } \\
\text { Average (0-1. Min) }\end{array}$ & $3.68 \pm 4.24$ & $29.78 \pm 29.86$ & 0.001 \\
\hline $\begin{array}{l}\text { Incorrect Compression } \\
\text { Average (1-2. Min) }\end{array}$ & $6.24 \pm 9.51$ & $51.8 \pm 46.25$ & $<0.001$ \\
\hline $\begin{array}{l}\text { BFS Average Score (end of } \\
\text { 1. min) }\end{array}$ & $10.29 \pm 0.84$ & $12.99 \pm 1.48$ & $<0.001$ \\
\hline $\begin{array}{l}\text { BFS Average Score (end of } \\
\text { 2. min) }\end{array}$ & $11.25 \pm 0.82$ & $13.18 \pm 1.60$ & $<0.001$ \\
\hline${ }^{*}$ Mann-Whitney U Test used & & & \\
\hline
\end{tabular}




\section{DISCUSSION}

Recently, the importance of both efficiency and time in CPR applications has become well understood. In addition, devices have been introduced in many CPR applications and continue to be used actively (10). In addition, the human factor on CPR is still emphasized. For this reason, factors affecting the effectiveness of healthcare professionals in CPR are being investigated (11). A few of these are BMI and BMW.

Examining the effect of physical fitness on chest compression, Ock et al. (12) measured the physical fitness parameters of the participants, such as maximal aerobic exercise capacity, muscle strength, and muscular endurance, and asked the participants to press the CPR trainer dummy continuously for 5 minutes.

Ock et al. (12) found that the percentage of correctly applied chest compressions decreased significantly after the first minute, and this percentage decreased continuously as the duration increased. However, they revealed that the number of correctly applied chest compressions was also related to muscle strength. Based on the research findings, Ock et al. (12) stated that exercise programs that increase muscle strength are important and necessary for CPR practitioners and for increasing the quality and effectiveness of CPR applied after cardiac arrest.

In our study, according to BMW, the fatigue of the participants at the end of the CPR period at the end of the 1 st and 2nd minutes was less in the participants with high BMW compared to the participants with low BMW, chest compression was higher in participants with high BMW, and appropriate chest compression was observed. It was observed that the number of BMW decreased in cases with low BMW and these numbers remained below the optimum desired numbers for CPR. Considering these results, it was seen that patients with low BMW could not complete even 1 cycle of 2 minutes of CPR while performing CPR, and it would be beneficial if a certain limit was set for BMW in CPR practice, and it would be beneficial to plan for the personnel performing $\mathrm{CPR}$ to participate in sports activities at regular intervals. was considered.

Another important finding obtained as a result of the study is that the chest compression is at superficial depth. Results 0-1 of rescuers with low BMW. and 1-2. showed that the number of superficial chest compressions applied between 1 and 2 minutes was significantly higher than the number of superficial chest compressions applied by rescuers with high BMW ( $\mathrm{p}=0.001$ and $\mathrm{p}<0.001$, respectively).

Some studies on the quality of chest compression have revealed that the compression is superficial. In the study conducted by Wik et al. (13) with ambulance personnel in 2005, they found that chest compressions could not be applied in half of the pre-hospital interventions applied to 176 adult patients, and most of the chest compressions applied were at a superficial level. Similarly, in the study conducted by Abella et al. (14) on 67 patients who underwent CPR by equipped and trained hospital personnel in the hospital, they revealed that $37 \%$ of the chest compression applied was superficial ( $<38 \mathrm{~mm}$.) (14).

Alspach, in his study on the quality of CPR in which he compared various studies, emphasized that chest compressions applied within the scope of CPR were applied superficially and below the recommended depth (15). Another finding on the quality and effectiveness of chest compression, one of the CPR parameters, was revealed in a study conducted by Brennan and Braslow in 1998. In a study conducted with 226 trainees participating in CPR trainings given by the American Red Cross and the American Heart Foundation, it was found that $50 \%$ of the participants applied chest compressions correctly at a rate of $2 \%$, and that most of the incorrectly applied chest compressions were caused by insufficient depth (16).

In the study conducted by Zhang et al. (17) in 2013 with the participation of 219 health personnel, it was revealed that one of the important factors affecting the quality of chest compression is gender. In the study, in which 77 male and 142 female healthcare professionals were applied, 2-minute chest compressions were applied on the manikin, it was determined that the average of the number of appropriate chest compressions and deep chest compressions of male participants was higher than that of female participants. In their research, they emphasized that the quality of chest compressions of female health personnel is lower than that of men. In addition, it was determined that female personnel received higher ACO scores than males and were more tired compared to this scoring.

In a study conducted by Lucia et al. (18) in 1999 examining the effect of the physical fitness of the rescuer on adequate CPR performance, 14 professional CPR rescuers with a sedentary lifestyle and 14 physically active rescuers inexperienced in CPR practice were put on a CPR trainer dummy for 18 minutes uninterrupted. compared chest compression application. As a result of the study, it was revealed that 4 people in the sedentary group could not complete the application due to pain and physical fatigue in the upper extremity, and they stated that a certain level of physical fitness of CPR rescuers is necessary and beneficial in order to maintain the effectiveness and quality of CPR in long applications.

In a systematic review examining simulation-based learning in nursing education, Cant and Cooper (19) and Sanchez (20) emphasized that simulation with medium 
and/or high reliability using a manikin is effective in teaching and learning when the practice guidelines are adhered to.

In an observational study conducted by Hokenek and Erdoğan (21) the results of thorax CT performed after cpr performed on non-traumatic cardiac arrest patients were compared and it was determined that the intrathoracic volume decreased in traumas secondary to cpr. Considering that patients with high BMI and BMW have a high risk of causing thoracic trauma in our study, we shouldnt forget that the important thing in CPR is not the weight and strength of the practitioner, but the speed and depth of compression in accordance with the recommendations of AHA 2020.

As a result, it was seen that BMW and BMI were important factors in the effectiveness of CPR in healthcare workers. It was observed that healthcare workers with high BMI and high BMI were less tired than those with low BMI. While no significant differences were observed in CPR parameters in BMI cases, it was observed that the number of appropriate compressions was significantly higher and the number of false compressions was lower in cases with high BMW. Again, it was seen that male participants had less fatigue than females and the fatigue was higher as the age increased.

\section{CONCLUSION}

It was thought that choosing the healthcare worker to perform CPR from people with high BMW or encouraging healthcare professionals working in units with frequent $\mathrm{CPR}$ to increase BMW through sports activities would increase the quality and effectiveness of $\mathrm{CPR}$ and pave the way for a decrease in mortality rates..

\section{ETHICAL DECLARATIONS}

Ethics Committee Approval: The study was carried out with the permission of İzmir Katip Çelebi University Non-Interventional Clinical Researchs Ethics Committee (Date: 27.05.2021, Decision No: 281).

Informed Consent: Because the study was designed retrospectively, no written informed consent form was obtained from patients.

Referee Evaluation Process: Externally peer-reviewed.

Conflict of Interest Statement: The authors have no conflicts of interest to declare.

Financial Disclosure: The authors declared that this study has received no financial support.

Author Contributions: All of the authors declare that they have all participated in the design, execution, and analysis of the paper and that they have approved the final version

\section{REFERENCES}

1. Balcı B, Keskin Ö, Karabağ Y. Kardiyopulmoner resüsitasyon. Kafkas Tip Bilimleri Derg 2011; 1: 41-6.

2. Topçuoğlu MA. Kardiyopulmoner arrestte serebral koruma. Yoğun Bakım Dergisi 2008; 8: 22-48.

3. Panchal AR, Bartos JA, Cabañas JG, et al. Part 3: Adult basic and advanced life support: 2020 American Heart Association Guidelines for Cardiopulmonary Resuscitation and Emergency Cardiovascular Care Circulation 2020; 142: 366-468.

4. Taş D, Akyol A. New trend in to cardiopulmonary resuscitation training: high-fidelity simulation. Turk J Card Nur 2017; 8: 100-8.

5. Roh YS, Lim EJ. Factors influencing quality of chest compression depth in nursing students. Int J Nurs Pract 2013; 19: 591-5.

6. Lukas RP, Engel P, Wecker S, et al. Cardiopulmonary resuscitation guidance improves medical students' adherence to guidelines in simulated cardiac arrest: a randomised cross-over study. Eur J Anaesthesiol 2013; 30: 752-7.

7. Steen PA, Kramer-Johansen J. Improving cardiopulmonary resuscitation quality to ensure survival. Curr Opin Crit Care 2008; 14: 299-304

8. Krikscionaitiene A, Pranskunas A, Stasaitis K, et al. Magical manoeuvre: a 5-s instructor's intervention helps lightweight female rescuers achieve the required chest compression depth. Eur J Emerg Med 2014; 21: 424- 8.

9. Krikscionaitiene A, Stasaitis K, Dambrauskiene M, et al. Can lightweight rescuers adequately perform CPR according to 2010 resuscitation guideline requirements? Emerg Med J 2013; 30: 159-60.

10. Wigginton JG, Miller AH, Benitez FL, Pepe PE. Mechanical devices for cardiopulmonary resuscitation. Curr Opin Crit Care 2005; 11: 219-23.

11. Meaney PA, Bobrow BJ, Mancini ME, et al. Cardiopulmonary resuscitation quality: improving cardiac resuscitation outcomes both inside and outside the hospital. Circulation 2013; 128 :417- 35.

12. Ock SM, Kim YM, Chung Jh, Kim SH. Influence of physical fitness on the performance of 5-minute continuous chest compression. Eur J Emerg Med 2011; 18: 251-6.

13. Wik L, Kramer-Johansen J, Myklebust H, et al. Quality of cardiopulmonary resuscitation during out-of-hospital cardiac arrest. JAMA 2005; 293: 299-304.

14. Abella BS, Alvarado JP, Myklebust $\mathrm{H}$, et al. Quality of cardiopulmonary resuscitation during in-hospital cardiac arrest. JAMA 2005; 293: 305-10.

15. Alspach G. CPR: the vanishing competency. Crit Care Nurse 2005; 25: 8-12.

16. Brennan RT, Braslow A. Skill mastery in public CPR classes. Am J Emerg Med 1998; 16: 653-7.

17.Zhang FL, Yan L, Huang SF, Bai XJ. Correlations between quality indexes of chest compression. World J Emerg Med 2013; 4: 54-8.

18. Lucía A, de las Heras JF, Pérez M, et al. The importance of physical fitness in the performance of adequate cardiopulmonary resuscitation. Chest 1999; 115: 158-64.

19. Cant RP, Cooper SJ. Simulation-based learning in nurse education: systematic review. J Adv Nurs 2010; 66: 3-15.

20. Sánchez B, Algarte R, Piacentini E, et al. Low compliance with the 2 minutes of uninterrupted chest compressions recommended in the 2010 International Resuscitation Guidelines. J Crit Care 2015; 30: 711-4.

21. Hokenek NM, Erdogan MO. Effect of differences in thorax volume and dimensions on CPR-related injuries. J Coll Physicians Surg Pak 2021; 31: 267-72. 